\title{
Treating High Conflict Divorce
}

\author{
Brenda J. Barnwell*, Mark H. Stone \\ School of Social Work, Aurora University, USA
}

Copyright $(0) 2016$ by authors, all rights reserved. Authors agree that this article remains permanently open access under the terms of the Creative Commons Attribution License 4.0 International License

\begin{abstract}
A model for treating high conflict in divorce is presented because the standard service model typically mandated is not sufficient to address the high stress dynamics residing in family systems or the self-concept of parents. The model for treating high conflict emanates from Bowen's family systems model and Kohut's theory of self-psychology. A strategy for client assessment and program evaluation is outlined together with an example showing the effectiveness of treatment for one sample of participants.
\end{abstract}

Keywords High Conflict Divorce, Bowen's Family Systems Model, Kohut's Theory of Self Psychology

\section{Treating High Conflict Divorce}

Social workers have long recognized the difficulties arising from divorce. Many people see divorce as stemming from a single condition or problem, such as infidelity, domestic violence, or addiction. Divorce is more complex, typically arising from far more complex conditions (Coontz, 2007) [1]. These varied conditions require targeted interventions for the family and for all individuals in the family system. The current model in judicial systems requires parents to participate in a curriculum established to address a broad range of issues, but rarely addressing family systems and individual dynamics.

\section{History and Status of Family Law}

According to provisional numbers provided by the National Vital Statistics System from the National Center for Health and Statistics (Center for Disease Control, NCHS, 2011) [2], the rate of divorces and annulments during 2011 was 3.6 per 1,000 of the total population. Approximately 877,000 dissolutions occurred out of a population of $246,273,366$. The numbers are provisional until further updates and analyses are conducted by the NCHS. More than a million children in the United States experience the divorce of their parents each year (U.S. Census Bureau, 2010).
According to Stevenson and Wolfers [4], "Divorce rates have risen while marriage rates have fluctuated around a relatively stable mean" (2007, p. 28). The number of highly contentious divorce cases consistently remains at ten percent of overall divorce cases (Kelly, 2000; Sandler, Miles, Cookston, \& Braver, 2008; Saini, 2012). While family law strives to lessen the intensity of animosity, eight to fifteen percent of divorcing couples continue to engage in conflict with little reduction in the intensity of their feelings (Deutsch \& Pruett, 2009; Hetherington, 1999; Hetherington \& Kelly, 2002; Johnston, Roseby, \& Kuehnle, 2009; Kelly, 2000; Maccoby \& Mnookin, 1992; Wallerstein \& Kelly, 1980). These extreme cases place great stress on children. Improving these conditions requires focused assessment and treatment to achieve therapeutic relief, resolution, and change.

All participants in the divorce process benefit from education to protect the safety and welfare of the child. Children need to know divorce is an adult decision. For parents to assist their children to adjust to changes occurring in the family from divorce, they must learn about their influence on children, especially so as single parents. Custody evaluators, attorneys and judges also require education concerning the limitations of theoretical frameworks, especially regarding "reciprocal connectedness" which is so vital to parent-child relationships as described by Arredondo and Edwards [14] (2000, pp. 109-110).

Currently, parents with children under the age of eighteen are usually court ordered to attend a class devised to assist in dealing with the impact of divorce on their children, and ways in which to behave to protect and assist their children. These classes have become "the standard service model" where all parents with children under eighteen years of age follow the same court order to attend such a course to obtain this information. The unique bio-psycho-social factors as well as cultural, spiritual and developmental matters of each parent are neither examined carefully, nor explicitly addressed. The latent assumption is that the standard service model will suffice these needs.

According to Luster and Okagaki, [15] "Even when parents are in conflict, cooperation in childrearing laws has been linked with healthier adjustment among children" (1993, p. 103). In 2000, Reid [16] addressed task-orientated 
topics usually presented in standard service classes. The list is likely to include:

1) accepting that some conflict occurs despite the best intentions of both parents;

2) determining what means of emotional expression will not involve the children when conflict arises;

3) learning about the effects of divorce on the entire family;

4) learning what the parents can do to help the children cope;

5) agreeing about information to be shared with the children concerning the divorce;

6) agreeing about the manner in which the information specific to the divorce was shared with the children;

7) recognizing the developmental needs of the children when talking about the changes in the family;

8) addressing breakdowns in communication, then acting in a manner to contain the conflict;

9) involving an objective third party, such as a social worker or a mediator if needed;

10) learning how to be a good role model by resolving conflicts rationally, maturely, and effectively.

A task-centered model is time-limited; restricting the number of tasks and goals that can be addressed in a limited time frame.

\section{The Family Life Cycle}

Bowen [17] imparted the idea that emotional functioning of members of a system must contend with anxiety due to constantly occurring changes (1978). Multi-generational transmission of anxiety perpetuates the stressors and anxiety unless family members break the cycle (Bowen, 1978). Unresolved anxiety passes from one generation to the next.

Divorces proceed with a similar pattern of anxiety transmission. Breaking this cycle of family disruptions and anxiety is especially important in divorce. When a treatment approach or intervention avoids these matters, the effectiveness of intervention is diluted.

\section{Social Work and the Judicial System}

The dissolution of marriage is complicated legally and emotionally for everyone involved. Bacon [18] shared the idea that conflict between parents has a significant influence on the process of adjustment for children (2004). The existing practices and policies of attorneys, judges and social workers within the family law system do not address individual needs, nor do they address the impact of the family system on children.

Further complications exist within the family law system. All parents seeking dissolution of marriage must take the standard model course, while parents who were never married are not obligated if the legal formality of marriage is not recognized. Prior to June 1, 2011, same-sex couples did not have to participate in court mandated classes in states where same-sex marriage was not recognized.

\section{An Intervention Model to Address High Conflict}

This intervention model is designed to address high conflict in advances beyond the standard service model. It addresses family systems and self-psychology because the family system and the unique person are integral parts of high conflict divorce. When parents are assessed and treated for the degree of conflict within the family system and their level of self-cohesion, a more definitive outcome results. Reducing the amount of parental conflict has beneficial effects on children.

Sessions should be conducted by a licensed clinical social worker due to the high level of potential conflict requiring a highly trained therapist. Groups of six to eight clients contract to attend eight weekly sessions for ninety minutes. Clients may include divorcing couples, and single parents. The frequency of sessions can also be scheduled to meet biweekly. This approach can be helpful by allowing participants a greater opportunity to integrate and practice concepts from the intervention sessions in their daily lives, and to allow for the process of change to occur and cohesion to grow. Each eight-week module may be extended by contracting for an additional eight-week session for clients' desirous or needing further treatment.

The curriculum for the sessions includes the following topics: empathy, self-cohesion, mirroring, idealization, twinship, circular causality, structure, patterns, emotional suppression, triangulation, and differentiation of the self. A pre- and post-session for assessment is also required (described below). Each therapy session begins with an experiential activity focused on the topic of the session followed by a related communication activity. Participants subsequently process these activities as a group. The final portion of each session includes time for journaling about the session, intended for application of the issues discussed. This activity is especially important by allowing each participant to reflect (in writing) on what occurred in the session and its personal meaning. The group facilitator follows the empathic approach recommended in Kohut's [19] self-psychology (1971). The clinical experience and practical orientation to family systems and self-concept formation makes this session meaningful to high conflict participants beyond what the standard service model can provide.

A pre- and post-session for assessment utilizes four instruments to permit a comprehensive evaluation of individual progress and for program effectiveness: (1) Group leader's attendance record and level of active participation. Participation level is rated high, medium, or low, and assessed as insightful, mundane, or non-participatory for each session and for the module summary. (2) PAM ${ }^{\mathrm{TM}}$ (Abidin \& Konold, 2001); (3) LOCA (Langenbrunner, Cox, \& Cherry, 2013); and (4) ASC (Barnwell \& Stone, 2015). 
Scores on the PAM ${ }^{\mathrm{TM}}$ indicate the level of parental alliance rated low, medium or high. A low score indicates deficient parental alliance with the co-parent. The scores on the LOCA report level of conflict rated low, medium or high with the co-parent. The ASC records the responses to items constructed from the essential concepts of Kohut's Self Psychology and Bowen's Family Systems Theory. The ASC was specifically designed to assess and identify deficiencies of self-concept and impairment in the family system deemed especially important in treating high conflict divorce.

The ASC total score provides an estimate of the degree to which the individual has become cohesive according to self-report. Conversion of the ASC total raw score to percentiles facilitates comparing the examinee's score to percentile scores derived from the frequency distribution of the normative sample. Percentiles indicate the percent of persons scoring at or below that score. $T$ scores compare an individual's score relative to the scores of those in the normative sample derived to have a mean of 50 and a standard deviation of 10. For example, a T score of 70 would indicate that the respondent's score is two standard deviations above the normative sample mean. A T score of 40 would indicate the respondent's score is one standard deviation below the mean. Scores between the $45^{\text {th }}$ and $55^{\text {th }}$ percentile are within the normal range of cohesion; the higher the ASC total score, the greater the level of cohesion. Table 1 gives the interpretative ranges for the ASC together with $\mathrm{T}$ scores, and percentile equivalents for raw scores.

Table 1. ASC Interpretive Categories and Corresponding $\mathrm{T}$ Score and Percentile Range

\begin{tabular}{|c|c|c|}
\hline Interpretation & T Score Range & Percentile Score Range \\
\hline Exceptional cohesion & Above 70 & Above 95 \\
\hline Above average cohesion & 56 to 70 & 63 to 95 \\
\hline Within normal limits & 45 to 55 & 22 to 62 \\
\hline Marginal cohesion & 40 to 44 & 10 to 21 \\
\hline Limited cohesion & 35 to 39 & 3 to 9 \\
\hline Absence of cohesion & Below 35 & Below 3 \\
\hline
\end{tabular}

Figure 1 gives the theoretical category for items of the ASC related to terms from Kohut's theory of Self Psychology together with a corresponding item stem.

\begin{tabular}{lll} 
Item \# & Category & Item Stem \\
\hline & & \\
1 & Mirroring & - support and encouragement from others. \\
14 & Mirroring & - share my feelings. \\
4 & Twinship & - seek out people. \\
18 & Twinship & - part of a group. \\
3 & Idealization & - seek role models. \\
10 & Idealization & - need to feel supported. \\
20 & Idealization & - prefer people like me. \\
12 & Empathy & - listen to the needs. \\
23 & Empathy & - attentive to fulfilling others. \\
30 & Empathy & - feel pain of others. \\
9 & Self Cohesion & - express true emotions. \\
22 & Self Cohesion & - more to give when feeling good. \\
29 & Self Cohesion & - found balance between needing being needed. \\
\hline
\end{tabular}

Figure 1. Categories of the Assessment of Self Cohesion (ASC): Self Psychology.

Figure 2 gives the theoretical category for each item of the ASC related to Bowen's Family Systems Theory with a corresponding item stem. 


\begin{tabular}{lll} 
Item \# & Category & Item Stem \\
\hline 2 & Triangulation & - express my emotions through others. \\
21 & Triangulation & - ask others to express my thoughts and feelings. \\
28 & Triangulation & - communicate best with help. \\
8 & Pattems & - notice the role I play. \\
19 & Patterns & - notice pattems from my family of origin. \\
5 & Structure & - the person who must make adjustments. \\
13 & Structure & - aware of roles people have. \\
25 & Structure & - role is clear. \\
6 & Circular Causality & - behavior is shaped by others. \\
15 & Circular Causality & - know who is to blame. \\
24 & Circular Causality & - influence the behaviors of others. \\
27 & Circular Causality & - parent who is responsible. \\
11 & Emotional Suppression & - do not express emotions. \\
16 & Emotional Suppression & - keep control of emotions. \\
7 & Differentiation of Self & - notice stress around me. \\
17 & Differentiation of Self & - responsible for reactions of others. \\
26 & Differentiation of Self & - attached to family. \\
& & \\
\hline
\end{tabular}

Figure 2. Categorical Form of the Assessment of Self Cohesion (ASC): Family Systems Theory.

Figures 1 and 2 are especially useful for diagnosing client responses to individual items to ascertain individual pre-treatment status and post-treatment gain (or loss). These concepts and respective items are as follows:

Empathy - Items 12, 23 and 30

Kohut's [23] operational definition of empathy is "the capacity to think and feel oneself into the inner life of another person" (1984, p. 82). Empathy allows one to know another's experience without misplacing one's objectivity. According to Basch, [24] derived from the German word Einfuhlung, empathy means "feeling into" or "searching one's way" toward knowledge of another (1983).

\section{Mirroring - Items 1 and 14}

Mirroring is a self-object need to be admired for one's qualities and accomplishments. In 1971, Kohut [19] stated that children need a caregiver who holds them in positive regard, admires them, rejoices in their progress, and congratulates their accomplishments. A healthy sense of grandiosity is achieved when this self-object need is met and valued by others producing pride in one's qualities and accomplishments.

Twinship - Items 4 and 18

The self-object need of twinship is a need to feel analogous to others. This need is met by engaging in relationships with those to whom one feels similar. Children need a caregiver to whom they have a sense of belonging. When a caregiver protects a child, the self-object need of twinship is satisfied. When an individual has the need of twinship met, the result is a sense of community and a sense of bonding.

Idealization - Items 3, 10 and 20

Idealization is a self-object need that is met when a sense of merging with idealized self-objects is achieved. Kohut [19] identified the need for children to hold onto an image of an idealized caregiver (1971). When a child feels respect and admiration for the admired parent, and the child identifies with the caregiver, this identification helps the child to develop in a secure manner because the child internalizes the principles.

\section{Self-cohesion - Items 9, 22 and 29}

Self-object needs must be met for a cohesive self to be established. Self-cohesion is achieved through innumerable transmuting internalizations of self-object functions into self-functions (Kohut, 1971). A healthy and cohesive self-structure is the outcome of normal development along the lines of grandiosity, idealization, and connectedness dimensions (Kohut, 1971, 1977, 1984).

Circular Causality - Items 6, 15, 24 and 27

In Bowen's [17] Family Systems Theory circular causality describes successive events whereby each event is caused by the previous one (1978). The goal is not to find blame, but to have family members acknowledge the problem, and work toward improved communication and resolution.

Triangulation - Items 2, 21 and 28

According to Bowen, [27] triangulation is a network or a behavior pattern that typically involves a pair of family members incorporating or rejecting a third family member. 
Cross-generational coalitions can also develop (1966). A triangle describes a three-person relationship system whereby the triangle becomes the "molecule" of larger emotional systems because it is the smallest stable relationship. Triangles exert social control by putting one person outside or introducing an outsider when tension escalates between two persons. Increasing the number of triangles may stabilize tension. Marital therapy uses the triangle to provide a neutral third party capable of relating to both sides of a conflict.

Emotional Suppression - Items 11 and 16

In 1972, Virginia Satir [28] described emotional suppression as the cause of family problems. An emotion regulation strategy occurs when true emotions are stifled, and pushed out of mind. Occasionally, when the strategy is used, negative consequences may not be the result. Unfortunately, when emotions are pushed away frequently, or all of the time, emotional suppression is likely to produce problems within the family.

Patterns - Items 8 and 19

Behavior patterns of family members tend to maintain predictable states within the boundaries of the system. The Bowenian [17] framework means that the therapist helps clients to look not only at patterns of relating over the generations but also to critique the roles they occupy in relationships.

Structure - Items 5, 13 and 25

Bowen's [17] Family Systems Theory focuses on the structure and workings of the system to enable the individual to move forward in a different systemic role. The multigenerational structure of a family system, roles and patterns offer information about the structure to assess and explain how each family member copes with anxiety.

Differentiation of Self - Items 7, 17 and 26

The first concept of differentiation of self-entails separating feelings from thoughts. Bowen's [10] progressive term, differentiation of self, leads to internal interplay between autonomy and connection. Fusion occurs when one person holds others responsible for how lives evolve. Fusion also involves difficulty separating one's own feelings and experiences from the feelings and experiences of others. The less developed a person's "self," the more impact others have on functioning and control. Bowen [17] described differentiation as the degree to which one emotionally joins another (1978). Reacting to conflict in a calm manner, accepting responsibility for the role played, and responding differently in the future are behaviors that represent differentiation.

\section{Treatment Model Evaluation}

An evaluation of the treatment model was conducted using a controlled study of one nine-week session. From eligible parents completing the standard service model, 32 were randomly selected and invited to participate in treatment sessions and were randomly assigned to the intervention group beginning immediately (experimental) or wait listed (control) to participate in a second round of intervention. The PAM $^{\mathrm{TM}}$, LOCA, and ASC were administered to all 32 participants. The correlation between the PAM ${ }^{\mathrm{TM}}$ and LOCA was -0.67 . These two instruments are inversely correlated whereby an increase in $\mathrm{PAM}^{\mathrm{TM}}$ scores for cooperation, communication and respect correlates to a decrease in LOCA scores indicating inter-parental conflict.

The correlation between the LOCA and the ASC was 0.18, and the correlation between the PAM ${ }^{\mathrm{TM}}$ and the ASC was -0.09. The two low correlations between the ASC and the LOCA, and the ASC and the PAM ${ }^{\mathrm{TM}}$, are interpreted to indicate that the ASC is associated with a different area of investigation from that measured by the LOCA and PAM ${ }^{\mathrm{TM}}$.

Data were further analyzed for a pretest-posttest measure of gain using the ASC as the dependent variable. The ASC was found to be statistically significant with regard to the gain scores computed between the experimental (treatment condition) and the control group (wait--listed treatment condition). Treatment outcome was viewed as positive according to improvement in gain scores for the experimental group as measured by the ASC. Table 3 gives this information. Substantial power and effect size indicate the value of this treatment approach.

Table 3. ASC: Two-Sample t-Test Difference in Gain Scores Assuming Unequal Variances

\begin{tabular}{ccc}
\hline & Control group & Experimental \\
\hline Mean Gain Score & 0 & 11 \\
Variance & 108.53 & 177.07 \\
SD & 10.42 & 13.30 \\
$\mathrm{~N}$ & 16 & 16 \\
Df & 30 & \\
t computed & -2.60 & \\
P & 0.01 & \\
t critical two-tail, $\mathrm{p}=.05$ & 2.05 & \\
Decision & Statistically significant & \\
Cohen's d (effect size) & 0.93 & \\
Power & 0.74 &
\end{tabular}

\section{Current and Future Research}

As the assumptions, limitations, and delimitations are presented, reviewing the purpose of this proposed mixed methods project may be helpful. The research attempted to reduce the conflict between divorcing parents. In addition, the experimental group experience attempted to increase a sense of self cohesion for participants. The research question follows: Does a focused treatment group based on the integration of Bowen's family systems theory and Kohut's 
theory of self-psychology reduce the level of expressed conflict and promote the cohesion of the self more than the standard service model? The goals of the intervention follow. People who attend eight sessions of the focused treatment group experience: (1) greater sense of self cohesion; (2) reduced co-parenting conflict; and (3) conflict reduction mediated by cohesion.

Several assumptions were present. The primary assumption was that divorcing parents involved in high conflict dissolution of marriage process are interested in participating in the experimental group. At the same time, one may assume that some participants might be uncomfortable with the highly charged nature of the topic. Another assumption includes the notion that parents involved in a high conflict state want to reduce the conflict. An additional assumption is that the parents want to begin the experimental group, and are willing to attend all sessions.

Limitations of the current research were identified under the external validity section. One limitation to the generalizability of the findings was the role of the volunteer participants. Length of marriage for each participant, and number of children may also have been limitations. Access to legal representation, as well as length of the divorcing process, are additional limitations. Another limitation was the eight sessions, time-limited group experience. The Saturday sessions may have prevented some volunteers from being involved in the experimental group. Future research may include a longer period for the intervention. The nature of self-reports may be a limitation for the study. The two established instruments, the PAM ${ }^{\mathrm{TM}}$ and the LOCA, as well as recently developed RSCI may be viewed as limitations too. Finally, the results and importance of this study are summarized in the discussion portion of the dissertation paper.

Other family dynamics could have been chosen for examination, but were not selected for several reasons. This research did not include parents in the dissolution of marriage process who have filed for divorce outside the specified county. The reason for the delimitation is due to the differences in the standard service model from county to county. In an effort to draw conclusions from the study, the sample of volunteers filed for divorce in the specified county located outside a large metropolitan area, and have taken the same mandated course that is the standard service model for the county cases.

Delimitations in the literature review included a review of the divorce process in other countries, a variety of populations, and the effect of divorce on children. Theoretical frameworks beyond Kohut's self-psychology and Bowen's family systems theory were not reviewed. The amount of theories available for a literature review was vast. Based on this writer's experience, clinical understanding, and academic awareness, this writer's integration of self-psychology and family systems theory seemed to be the most fitting to potentially increase self-cohesion and reduce parental conflict. This researcher did not find any instruments that measured alliance, conflict, and self-cohesion in the same instrument. As a direct result, the $\mathrm{PAM}^{\mathrm{TM}}$, the LOCA, and the ASC were incorporated into the study. Many potential secondary research projects remain possible. Additional populations, age groups, including attention on children are possible studies for the future.

The results of this study could be generalizable to (a) parents (b) of children under the age of 18 years, (c) seeking to dissolve a marriage who (d) resides in a county, (e) outside a large metropolitan area. The results are not generalizable to other populations.

\section{Summary}

High conflict divorce cannot be addressed by the standard service model which offers parents only a beginning introduction to coping with legal separation and assuring dependent children a safe and non-toxic environment. A specialized service model was presented that addresses family systems and individual self-concept which provides parental insight into family dynamics and personal self-worth. Assessment tools and program evaluation indicate this model has potential for addressing the needs of parents coping with high conflict divorce.

\section{REFERENCES}

[1] Coontz, S. (2007). The origins of modern divorce. Family Process, 46(1), 7-16. doi: 10.1111/j.1545-5300.2006.00188.x

[2] Centers for Disease Control and Prevention. (2011). Marriage and divorces. Public-use data file and documentation. Retrieved from: http://www.cdc.gov/nchs/mardiv.htm, November 1, 2013.

[3] U.S. Bureau of Census (2010). Statistical abstracts of the United States. Washington, DC: Government Printing Office. Author.

[4] Stevenson, B. \& Wolfers, J. (2007). Marriage and divorce changes and their driving forces. Working Paper 12944, National Bureau of Economic Research, Cambridge, MA. Retrieved from: http://www.nber.org/papers/w12944

[5] Kelly, J. (2000). Children's adjustment in conflicted marriage and divorce: A decade review of research. Journal of the American Academy of Child \& Adolescent Psychiatry, 39 (8), 963-973. doi: 10.1097/00004583-200008000-00007

[6] Sandler, I., Miles, J., Cookston, J., \& Braver, S. (2008). Effects of father and mother parenting on children's mental health in high- and low-conflict divorces. Family Court Review, 46(2), 282-296. doi: 10.1111/j.1744-1617.2008.00201.x

[7] Saini, M. (2012). Reconceptualizing high-conflict divorce as a maladaptive adult attachment response. Families in Society, 93(3), 173-180. doi: 10.1606/1044-3894.4218

[8] Deutsch, R. \& Pruett, M.K. (2009). Child adjustment and high conflict divorce. In R. M. Galatzer Levy and L. Kraus (Eds.), the scientific basis of custody decisions ( $2^{\text {nd }}$ ed., pp. 353-374). New York: Wiley. 
[9] Hetherington, E. M. (1999). Should we stay together for the sake of the children? In E. M. Hetherington (Ed.), Coping with divorce, single parenting, and remarriage: A risk and resiliency perspective. (pp. 93-116). Mahwah NJ: Erlbaum. NY, US: W.W. Norton \& Co.

[10] Hetherington, E., \& Kelly, J. (2002). For better or for worse: Divorce reconsidered. New York, NY, US: W.W. Norton \& Co.

[11] Johnston, J.R., Roseby, V. \& Kuehnle, K. (2009). In the name of the child: A development approach to understanding and helping children of conflicted and violent divorce. (Second Ed.). New York: Springer Publishers.

[12] Maccoby, E. E. \& Mnookin, R.H. (1992). Dividing the child: Social and legal dilemmas of custody. Cambridge, MA: Harvard University Press.

[13] Wallerstein, J., \& Kelly, J. (1980). Surviving the breakup: How children and parents cope with divorce. New York, NY: Basic Books.

[14] Arredondo, D. E. \& Edwards, L.P. (2000). Attachment, bonding, and reciprocal connectedness. Limitations of attachment theory in the juvenile and family court. Journal for the Center for Families, Children and the Courts, 2 109-129. Retrieved from: http://www.courts.ca.gov/documents/CFCC_Journal2_.pdf

[15] Luster, T. \& Okagaki, L. (1993). Parenting: An Ecological Perspective. Hillsdale, N.J.: Lawrence Erlbaum Associates.

[16] Reid, W. (2000). The task planner. An intervention resource for human service professionals. New York, Columbia University Press.

[17] Bowen, M. (1978). Family therapy in clinical practice. New York: Aronson.
[18] Bacon, B. L. (2004). Multidisciplinary perspectives on parent education after separation and divorce. Social Work Forum, 37, 43-62. doi: 10.1177/1531244504421007

[19] Kohut, H. (1971). The analysis of the self: A systematic approach to the psychoanalytic treatment of narcissistic personality disorders. Chicago, IL: University of Chicago Press.

[20] Abidin, R., \& Konold, T., (2001) Parenting Alliance Measure $^{\mathrm{TM}}$, Psychological Assessment Resources, Inc. Odessa, Florida.

[21] Langenbrunner, M. R., Cox, M., \& Cherry, D. (2013). Psychometrics of LOCA: Level of conflict assessment of divorcing or separating couples. Journal of Divorce \& Remarriage, 54(6), 439-457. doi: 10.1080/10502556.2013.8 10978

[22] Barnwell, B. \& Stone, M. (2015). Assessment of self-cohesion. International Journal of Research in Humanities and Social Studies, 2 (9), 17-26.

[23] Kohut, H. (1984). How does analysis cure? Chicago: University of Chicago Press.

[24] Basch, M.F. (1983). Empathic Understanding: A Review of the concept and some theoretical considerations. Journal of the American Psychoanalytic Association, 31, 101-126. doi: 1984-01905-001

[25] Kohut, H. (1977). The restoration of the self. New York: International Universities Press.

[26] Bowen, M. (1966). The Use of Family Theory in Clinical Practice. Comprehensive Psychiatry, 7, 345-374.

[27] Satir, V. (1972). People making. Palo alto, CA: Science and Behavior Books 